KEMAS 12 (1) (2016)11-17
Jurnal Kesehatan Masyarakat

\title{
THE ANALYSIS OF SCHOOL HEALTH DEVELOPMENT INDEX (SHDI)
}

\author{
Made Agus Dharmadi ${ }^{\bowtie}$ \\ Faculty of Sports and Health, Ganesha University of Education
}

\begin{tabular}{l} 
Article Info \\
\hline Article History: \\
Submited November 2015 \\
Accepted January 2016 \\
Published July 2016 \\
\hline Keywords: \\
SHDI; Health \\
Development; School \\
\hline DOI \\
http://dx.doi.org/10.15294/ \\
kemas.v12i1.4021 \\
\hline
\end{tabular}

\begin{abstract}
The grand strategy of the Ministry of Health is the proper functioning of evidence-based health information systems through basic data and indicators. Therefore, this study aims at formulating an analysis of the needs, dimensions and indicators of School Health Development Index (SHDI). The samples included 50 schools for all units of educational levels in Buleleng Regency. The study employed the method of participant observation, documentation studies, interviews and questionnaires. Based on the results and discussion, it can be concluded that 1) Healthy school is a fixed price for every school, 2) The understanding of School Health Index Development (SHDI) of UKS supervising teachers in schools is still lacking, 3) the use of SHDI in every school is very important to measure the level or health status of each school in Buleleng Regency 4), The dimensions of SHDI are a) School policy, b) Work Program, c) Infrastructures, and d) School community behavior, 5) The existence of the SHDI guidebook becomes one of the bases for SHDI achievement.
\end{abstract}

\section{Introduction}

One of the grand strategies of the Ministry of Health is the functioning of evidence-based health information systems through basic data and indicators. The indicators can represent a picture of the national, provincial and regency/ city territories even other regions related to their health status and determinants based on the concept of Hendrik L. Blum consisting of four determinants such as behavior, heredity, environment, and health services. However, to date, the health information centers are still very difficult to do such mapping.

School is a formal and strategic institution to prepare human resources which are healthy physically, mentally and socially in order to become productive human beings. At school, there are two processes at the same time namely learning and education for students. Learning is a process of learners' interaction with educators and learning resources aiming at improving the cognition of learners; whereas education is the process of developing positive capabilities and shaping the character of learners. Educational success is determined by many factors and one of those factors is healthy condition of school and environment.

On the other hand, this year, the empowerment and synergism of coordination between central and local governments in accelerating the implementation of health development is very central to achieve the target of National Medium Term Development Plan (RPJMN) 2010-2014 and the Millennium Development Goals (MDGs), and to realize healthy, independent and fair society. Therefore, health information system between center and regional governments should be collaborated effectively in creating development of health indicators which are valid and reliable (Kementrian Kesehatan, 2010).

Health development must be performed in all aspects including education. Health should be addressed as Global Health, so overall health for all can be achieved (Ooms et al, 2014). Ministry of Education has recently

\footnotetext{
$\triangle$ Correspondence Address:

Faculty of Sports and Health, Education University of Ganesha, Bali

Email : made_agus2011@hotmail.com
} 
proclaimed that the synergism of health and education is urgently necessary to be done in order to achieve the educational goals in formulating comprehensively intelligent and healthy individuals both physically and mentally according to the demands of the Constitution of 1945. Education through the organization of the school is the frontline units to create healthy individuals and groups who become reflection of a whole society including teachers, principals, students, employees and others who are part of the broader community. In the present school, students are the future generation and assets of nation. Health education needs to be pursued since school age because school has an important role in delivering health information to students and community. Healthy behavior is a habit that needs to be inserted early and must start from parents, children and teachers at the schools. Successful public health can be established with the collaboration between environment, health scientists through social and economic activities as well as government (Reis et al, 2014). According to Ko, Y.J et al (2014), an effort to minimize mortality is conducted by intervening health society through health education (school).

Responding the number of cases related to nutritional adequacy of students which make students malnourished and obese, Waltona et al (2013) states that the role of school policy is very important in minimizing the occurrence of malnutrition and obesity at school. Collaboration between parents, teachers, students, leaders, community health agencies and other stakeholders will greatly assist the completion of the above objectives (Larrier et al, 2013). Moreover, the World Health Organization (WHO) states that the control of the spread of diseases such HIV, Malaria, TB, Drugs, Smoking in public is the target of the WHO program in the future (Sridhar et al, 2014).

School is an element that is central in searching the existing information and resources at schools, one of which is the teachers and students. Based on the findings of Solehati (2015), teachers' knowledge, skills and personal hygiene of student need to be improved in order to foster Clean and Healthy
Lifestyle (PHB) within community. Besides, the construction of quality school is slowly decreasing which means that the adaptation of regulations at schools is often neglected, for example the minimal acreage of school and narrow layout of the building. There are even some schools which are located within dense housing complexes. Several schools now prefer to seek out students as many as possible to get the funding sources and claim more recognition from schools other than paying attention to the quality of schools. Those are also one of the reasons why the school should be pursued to be made more quality in terms of a healthy school from the provision of infrastructure and other supports to improve the health development of integrated schools.

Based on the above background and in order to develop an evidence-based grand strategy, this study entitled "Developing School Health Development Index (SHDI) in Buleleng Regency to Improve the Integrated School Health Development is very urgent to be done immediately.

\section{Method}

This study used research and development design and modified several stages of development namely Stage I (in 2014): 1) investigating and collecting information about the needs analysis, 2) planning dimensions and indicators that would be developed including defining, formulating goals, determining the sequence of events and making SHDI components, 3) developing components and early indicators of SHDI, 4) validating the components and indicators SHDI for the experts, 5) revising and providing indicators and components for SHDI. Stage II (in 2015) consisted of: 1) investigating and collecting information about the needs analysis of SHDI, 2) planning instruments that would be developed including defining, formulating goals, determining the sequence of events and making the research instruments, 3) developing instruments SHDI, 4) validating instruments of SHDI for the experts, 5) revising SHDI instruments based on the input of experts. Stage III (in 2016) involved a limited test (phase I) instrument SHDI, 6) evaluating and revising the instruments of SHDI based on 
the test results and data analysis, 7) collecting the data in the field/school based on the feasible instruments from the limited testing, (8) presenting the results and conclusions, 9) creating and disseminating research reports to various parties.

In detail, the phases can be explained on the following lines of inquiry:

The above figure shows the overall design for three years, and this article is the result of research that has been done in the first year of SHDI development In Buleleng Regency.

The samples were randomly selected and chosen proportionally in each district. Hence, from the existing population, the samples of this study were 20 elementary schools, 20 junior high school, 7 senior high school and 3 vocational high schools. There were 50 schools in total throughout the unit levels of education in Buleleng Regency.

The data collection technique is a means of measuring instruments required in carrying out an investigation. In this study, the data collection techniques were carried out using participant observation, study of documentation, interviews and questionnaires.

This research data was in the form of quantitative and qualitative data and therefore the processing of data using qualitative methods were used in the data that required a narrative meaning both the content and the process. In accordance with the methods of qualitative data analysis, the steps of data analysis involved: (1) after the data was collected, the author conducted data reduction by summarizing field reports and noting the major issues that were relevant to the focus of the research, (2) developing a systematic way by categories and specific classification, (3) creating the display data in the form of tables or graphics so that the relationship among the data were clear intact (not separated), (4) conducting crosssite analysis by comparing and analyzing the data in depth and (5) presenting the findings and drawing conclusions in the form of the general trend and the implications of its implementation as well as recommendations for the development.

\section{Results and Discussion}

Based on the interviews, observations and questionnaires distributed to schools about healthy schools, the results of this study can be described as follows:

Based on the above figure, it can be concluded that all schools have prioritized the healthy school. This is because the school is their second home for living and learning activity every day. All teachers (100\%) state that a healthy school is important. By having a healthy condition at school, a fun learning environment can be created and it will explicitly foster students' motivation in school so that learning objectives can be achieved. The condition of healthy school is not limited only on the infrastructure but also policies. Education system must fully support the creation of a healthy school.

Maintaining open space is one of the policies that should be created, in order to create a space for interaction and social capital to foster students' performance. Widowati (2015) reveals that social capital gives influences on students' achievement. The addition of classrooms/new buildings which sacrifices open space of schools should be eliminated. The addition of badly-managed classroom spaces will narrow the open space for students to interact each other. This action will affect the quality of interaction and psychologically increase the boredom among students as there is no alternative other than the classroom interaction. Therefore, a healthy school is a fixed price for educational institutions, so that a good academic atmosphere can be realized.

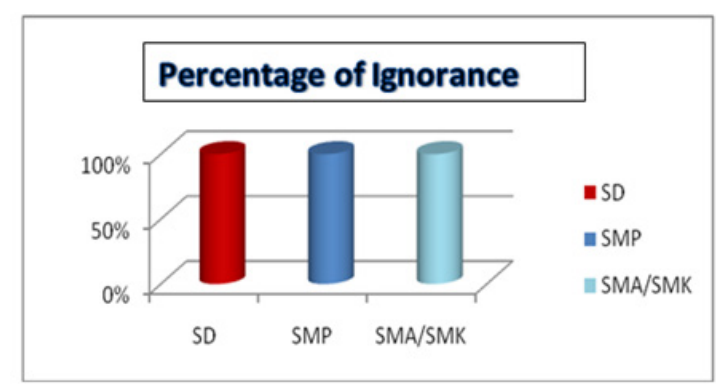

Figure 3. Profile of Understanding of School Health Development Index (SHDI)

Based on the above picture, all of the respondents (100\%) which are responsible for the field of school health in this case do not have an understanding of SHDI yet. They do 


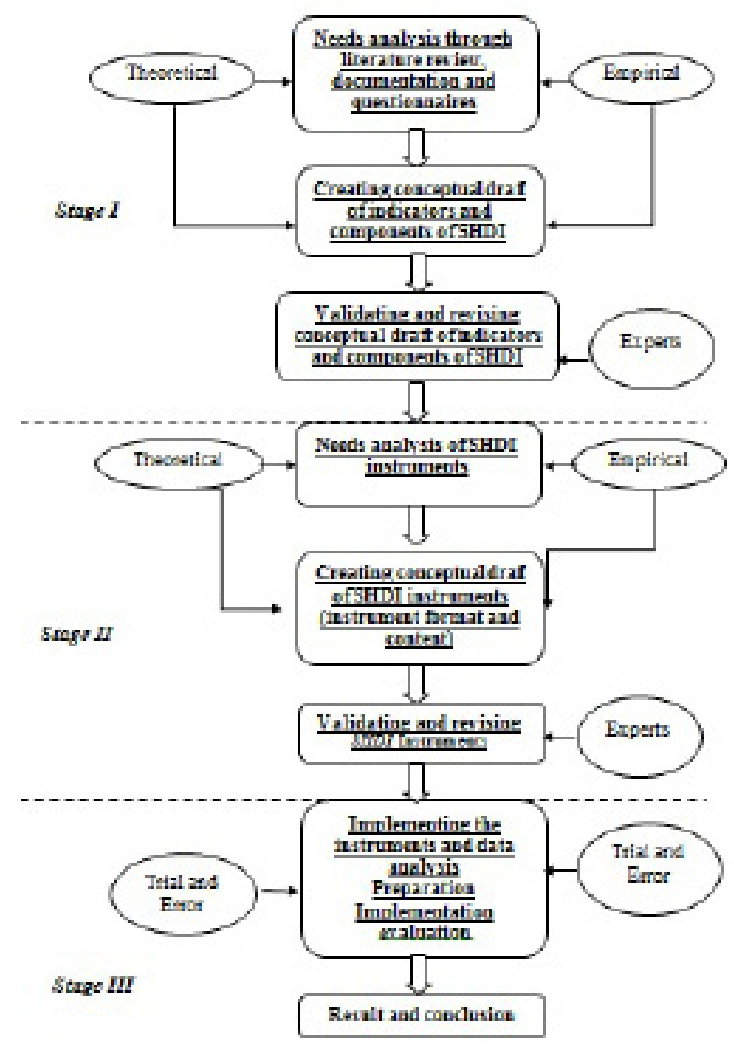

Figure 1. Flow of Research Development

not understand of what and how to prepare SHDI. This indicates that the concept SHDI contains a novelty in health which is integrated within education. Therefore, the synergy between education and health should be strong and sturdy. The education process will help regenerate health and vice versa. SHDI is an invention of researchers in creating valid data about the quality of school in the current era, including determining the direction and trend of educational units in the country in school management.

Indication for gaining more profit at the expense of quality school is occurring. Therefore, with the expected SHDI, such thing can be prevented. The existence of SHDI will play a very central role in the midst of school competition and the era of the ASEAN Economic Community (AEC) today. Other findings indicate that the importance of providing a SHDI understanding for the school is inevitable. It is important that SHDI concept is presented to the school starting from the elements of school leaders to the students. This effort will allow a healthy culture that is shared by all components in the school. Hence, the whole purpose of education to create a smart and healthy human being can be accelerated.

From the figure 4, it can be concluded that, for infrastructure 1) school buildings for elementary, junior and senior high schools are classified as good (average 80\%), while sanitation is quite good (average 60\%), WC/ bathroom is lacking (average 50\%), the condition of school health unit (UKS) is lacking (average 45\%), cafeteria is classified as good (average 70\%), school environment is quite good (average 73\%) and water resources and sanitation are classified as very good (average $85 \%)$. The above findings have indicated in real terms that SHDI really is needed at this time. SHDI will be an accurate reference in creating a healthy school and preventing additions classrooms only to seek profit. With the above data, the efforts to improve the conditions are still lacking (WC and toilets), as well as sanitation facilities is quite necessary, while increasing and maintaining the conditions which have been already good should also be encouraged. The above preliminary data shows that the importance of SHDI in this country exists. Therefore, comprehensive SHDI will answer all the problems in the education unit which would certainly make this SHDI as the first reference for the development of schools in the future.

In the efforts to foster a culture of being clean and healthy at school, the indicators used are 1) socialization which is done to improve the culture of clean and healthy living at schools, 2) activities of school leadership in supporting the culture of a clean and healthy, 3) activities of teachers in supporting clean and healthy living, 4) activities of employees to support a clean and healthy living, 5) student activities in supporting clean and healthy living.

Based on the results of the literature study, interviews and questionnaires which have been conducted, the results are as follows: 1) socialization which are conducted by schools in improving the culture of clean and healthy living is relatively minimum as a whole, the existing efforts are for example creating the schedules of cleaning for students at certain times such as Friday morning. 2) The leaders of the school implement clean and healthy living through several policies targeting the action 


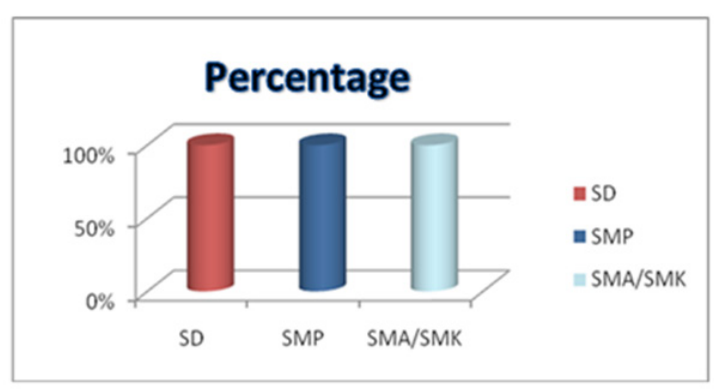

Figure 2. The Profile of Importance of Healthy Schools for Teachers

cleanliness efforts which are jointly conducted regularly. 3) Teachers are more dominant as advice givers related to the importance of clean and healthy living behavior to students. 4) The employees tend to follow the direction of school leaders related to the culture of clean and healthy living. 5) Students are conducting healthy and clean living behavior through several activities such as student council, scouting, as well as other extra-curricular activities.

The dimensions of SHDI based on the implemented analysis are a) the school policy, b) Work program, c) Infrastructures and d) school community behavior. Educational policy is the embodiment of the vision and mission of the school. School policy should be in line with national and regional policies set out in the collective agreement $(\mathrm{MoU})$ between the directorate for school management with the local, provincial and district/ city government. School policies are drafted and agreed upon by the school community and the school committee in order to guarantee the implementation of Healthy Schools program. Kemendikbud (2015) states that the policy serves as the reference in developing and implementing healthy schools for the entire school community. Based on the policy of the Directorate of School Management on Healthy Schools Program, the school has a foundation to organize programs of clean and healthy lifestyle behaviors on an ongoing basis. School is obliged to preserve their cleanliness and hygiene such as classrooms, courtyards, school environment and others through the implementation of various activities related to nutrition and health, health services (UKS), a clean environment, or other activities.

Work program of healthy schools is the embodiment of the vision, mission, goals that have been determined. Vision, mission, and objectives are stated in the school program plan, activities and budget plans that involve the active participation of all citizens and school committees. Monitoring and evaluation of the plan and the implementation of the program are needed in order to evaluate the program and serve as the basis for the improvement and development of next program. School programs will be achieved through the acculturation of clean and healthy living behaviors, building management, school environment, school programs planning, and supported by the school management, facilities and infrastructure, and the involvement of various parties. The success of this program is determined by the commitment of the whole school community depicted from the vision, mission, goals, programs and school activities. Principles of healthy school work program include aspects of the provision of facilities/ infrastructure, habituation of clean and healthy behavior, child-friendly atmosphere, environmental education, nutrition and health education, as well as health services. In planning healthy school program, schools need to involve and utilize human resources and other resources, including the infrastructures that have been owned by the school as a basis for designing the program.

Schools optimize the infrastructure that supports clean and healthy living behavior. Facilities and infrastructure must be adapted to the standard of existing legislation, namely the National Education Minister Regulation Number: 24 of 2007 and Decree of the Minister of Health number: 1429/Menkes/SK/XII/2006 regarding Implementation Guidelines of School Environmental Health, as well as the Regulation of the Minister of Women's Empowerment and Child Protection No 82014 on child friendly Schools Policy.

Healthy Schools Program is supported by child-friendly infrastructure such as buildings consisting of the principal's office, staff room, library, classrooms, a bathroom/ WC, infirmary, cafeteria, warehouses, places of worship, yard, and the school fence. All units in the school building must be free from noise which destructs concentration of learners and the comfort of the learning process. 


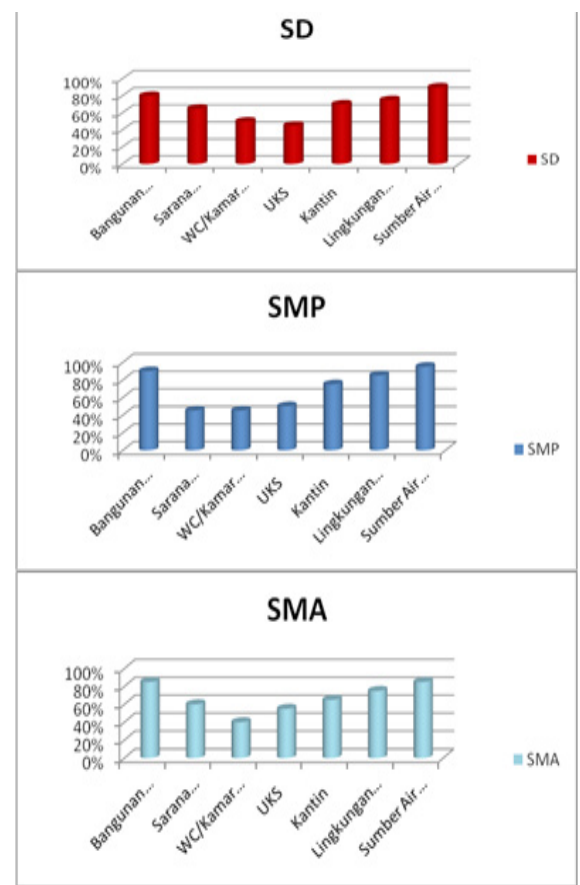

Figure 4. Profile of Healthy School Infrastructures

The goal of healthy school implementation is to cultivate a clean and healthy living behavior. Here is an example of hygienic behavior and healthy school communities such as keeping the hair clean and neat, wearing clean and neat outfits, keeping nails short and clean, exercising regularly, not smoking and drinking alcoholic beverages (MINOL), not using narcotics, psychotropic and addictive substances (NAPZA), eradicating mosquito larvae, using clean and healthy latrines, using clean water, washing hands with water and soap, throwing garbage into separate bins (organic and inorganic), consuming healthy and nutritious food, measuring weight and height periodically.

From the obtained results and based on the SHDI dimensions and indicators, the guidebook has been prepared based on the study of literature and is examined by two experts consisting of experts on the guidebook and health sector. The guidebook consists of cover, preface, introduction (background, legal basis, objectives and benefits, systematics), the basic concept of healthy schools, and basic concept of SHDI. From the test results of expert, the input range associated with the background, objectives and benefits and basic concepts SHDI are obtained. Education has the task to transform and prepare human resources development. One of them is in the development of health. Therefore, education through schools has a very important role. School is a place to educate students to create bright, healthy and noble human resource. Health education in schools is one part of the curriculum so that every school has an obligation to maintain the availability of the existing resources. The data shows that children of school age are particularly vulnerable to health problems. Hence, the existence of a healthy school becomes inevitable.

Healthy schools should have a basic standard so that their operations can be done without causing confusion for the whole school component that implements it; starting from infrastructure, space order, reception mechanisms of student / teacher and others. By following the existing standards, it is expected that the school can run the process with quality education so that later it can create students with high competitiveness.

The availability of schools with good health standards will ensure the achievement of the holistic health development. One of the school's roles in health development is School Health Unit (UKS). UKS is a unit which is in charge of matters related to public health in schools, students, teachers, principals and school staff, and is also used as a unit by health programs to achieve health development. The 
objective of UKS is to improve the healthy living behavior in students and school environment so that they can learn, grow and develop as quality human resources. In addition to UKS, the students who are also the nation's assets are forefront troops of health development. Therefore, students are the key element in the school and will be major elements for the development of the nation's health.

School Health Development Index (SHDI) is an innovative idea of researchers which is inspired from the stagnant various elements of measurement used to determine level of development of a nation, such as the measure that is often used to compare the success of the development of human resources between countries such as Human Development Index (HDI). The index is a composite indicator comprising; health indicators (life expectancy at birth), education (literacy rate and school) and the economy (real spending per capita).

\section{Conclusion}

Based on the obtained results and discussion, the conclusions of the study are: 1 ) Healthy School is a fixed price for every school in the Buleleng Regency from elementary, junior high, or senior and vocational high school. 2) The understanding of the School Health Index Development (SHDI) of UKS supervising teachers in SD, SMP and SMA is still lacking. 3) SHDI in each school is very important to measure the level or degree of health of each school in the Buleleng Regency. 4) The dimensions of SHDI based on the analysis which is done are a) school policy, b) work program, c) infrastructure and d) school community behavior. 5) The existence of the
SHDI guidebook becomes one of the bases for SHDI achievement.

\section{References}

Kemendikbud. 2015. Panduan Pembinaan Penyelennggaraan Sekolah Dasar Bersih dan Sehat. Dirjenndikdas: Jakarta

Kementerian Kesehatan. 2010. Rencana Strategis Kementeria Kesehatan Republik Indonesia 2010-2014

Ko,Y, et all. 2014. Effect of Employment and Education on Preterm an Full Term Infant Mortality in Korea. Public Health Journal, 128 (3)

Larrier,Y and Kijai,J. 2012. School Counselor Perspectives of The Barries And Facilitators Associated with Their Involvement in the Childhood Obesity Evidemic. Health Education Journal..43 (4): 218-225

Ooms,G, Marten,R, Hammonds,R et all. 2014. Great Expectations for WHO: a Framework Convention On Global Health to Achieve Universal Health Coverage. Public Helath Journal.Online.128 (2)

Reis,S, Morris, G et all. 2014. Integrating Health and Enviromental Impact Analysis, Public Health Journal, 118 (4)

Solehati,Tetti, dkk. 2015. Pengaruh Edukasi Terhadap Pengetahuan dan Skill Guru Serta Personal Hygienes Siswa SD. Jurnal Kesehatan Masyarakat 11 (1):135-143.

Sridhar,D and Gostin, L. 2014. World Health Organization (WHO): Past, Present and Future. Public Health Journal, Online. 128 (2)

Waltona,W and Signalb,L.2013. Public Policy to Promote Healthy Nutrition in Schools: Views of Policymakers. Health Education Journal, 72: 3283-291

Widowati,Atri, 2015. Modal Sosial Budaya dan Kondisi Lingkungan Sehat Dalam Pembinaan Prestasi Olahraga Pelajar. Jurnal Kesehatan Masyarakat 10 (2):118-226. 